\title{
DESOXIDAÇÃO PARCIAL COM COQUE DOS AÇOS BAIXO CARBONO ACALMADOS AO ALUMÍNIO*
}

\author{
João Domingos Guimarães de Athayde Júnior ${ }^{1}$ \\ Aquiles Jorge ${ }^{2}$ \\ Ivan Lopes Alves ${ }^{3}$ \\ Sílvio Teixeira de Alcântara Filho ${ }^{4}$
}

\begin{abstract}
Resumo
A prática de desoxidação dos aços durante o vazamento, na qual se utiliza o alumínio como desoxidante é bastante difundida entre os aciaristas. Entretanto, gera-se como produto da desoxidação a alumina $2 \underline{\mathrm{Al}}+3 \underline{\mathrm{O}}=\mathrm{Al}_{2} \mathrm{O}_{3(\mathrm{~s})}$. Na maioria das vezes, a alumina compromete a qualidade interna do produto, assim como a lingotabilidade do aço líquido elaborado. Estas inclusões não metálicas contribuem para a obstrução da válvula submersa durante o lingotamento. Visou-se neste trabalho avaliar o potencial da substituição de parte do alumínio pelo coque na desoxidação parcial dos aços baixo carbono acalmados ao alumínio durante o vazamento do metal dos convertedores para a panela. Após o desenvolvimento da metodologia e do procedimento operacional, utilizou-se o coque como pré desoxidante em 868 corridas, no período de 09/2014 a 02/2015, sem a ocorrência de reações durante a adição de coque no vazamento e sem o comprometimento do acerto da composição química.
\end{abstract}

Palavras-chave: Aço baixo carbono; Alumínio; Desoxidação parcial; Coque.

\section{PARTIAL DEOXIDATION WITH COKE OF ALUMINUM KILLED LOW CARBON STEELS}

\section{Abstract}

The deoxidation practice of steel during the tapping, which aluminum is used as a deoxidizer, is widespread among steelmakers. However, alumina is generated as deoxidation product: $2 \underline{\mathrm{Al}}+3 \underline{\mathrm{O}}=\mathrm{Al}_{2} \mathrm{O}_{3(\mathrm{~s})}$. Most of the times, alumina is a problem for the internal quality of the product and also for the castability of liquid steel. Those nonmetallic inclusions promote clog formation at submerged entry nozzle (SEN). This study evaluated the partial replacement of aluminum by coke in deoxidation of Alkilled low carbon steels during the tapping. After the methodology and the operational procedures development, coke was used as a pre-deoxidizer in 868 heats, from $09 / 2014$ to $02 / 2015$, without the occurrence of reactions during the addition of coke in the tapping and without compromising the accuracy of the chemical composition.

Keywords: Low carbon steel; Aluminum; Partial deoxidation; Coke.

\footnotetext{
Engenheiro Metalurgista, Msc, Especialista de Produção Pleno, Usiminas Ipatinga, MG, Brasil. Engenheiro de Materiais, Supervisor de Produção, Usiminas Ipatinga, MG, Brasil.

Engenheiro Mecânico, Assistente Industrial, Usiminas Ipatinga, MG, Brasil.

Técnico em Eletrônica, Técnico de Automação e Controle, Usiminas Ipatinga, MG, Brasil.
} 


\section{INTRODUÇÃO}

A desoxidação dos aços via adição de alumínio durante o vazamento do convertedor para a panela é bastante difundida entre os aciaristas. É sabido que o produto desta desoxidação gera alumina. A reação de desoxidação pode ser representada pela equação (1):

$$
2 \underline{\mathrm{Al}}+3 \underline{\mathrm{O}}=\mathrm{Al}_{2} \mathrm{O}_{3(\mathrm{~s})}
$$

A alumina gerada no processo de desoxidação é a causa raiz das obstruções de válvulas submersa, estejam elas na forma de alumina propriamente dita, aluminatos e/ou espinélio [1]. Além disto, a presença destas inclusões não metálicas prejudica a qualidade interna e superficial dos aços e a lingotabilidade devido às obstruções da válvula submersa. Para reduzir a quantidade de alumina no banho líquido, os aciaristas têm adequado as escórias de refino secundário no sentido de aumentar seu potencial de absorção de inclusões. Também tem sido relatados investimentos em práticas de injeção de argônio para maximizar a flutuação das inclusões [2].

Dado que a alumina é gerada no processo de desoxidação e é a principal causa dos problemas relacionados à lingotabilidade dos aços, visou-se neste trabalho a redução da formação desta alumina via substituição parcial do alumínio pela adição do coque durante o vazamento do aço líquido do convertedor para a panela.

A reação do carbono contido no coque com oxigênio dissolvido no metal líquido pode ser representado pela equação (2):

$$
\underline{\mathrm{C}}+\underline{\mathrm{O}}=\mathrm{CO}_{(\mathrm{g})}
$$

Neste caso o produto da desoxidação é o $\mathrm{CO}_{(\mathrm{g})}$, que não é incorporado no aço líquido; ou seja, o produto desta desoxidação não prejudica a limpidez e a lingotabilidade do aço líquido e nem a qualidade do produto. Um melhor entendimento do uso de desoxidantes requer uma análise de solubilidade dos produtos da desoxidação. A quantidade e tipo do produto da reação dependem da temperatura do aço e da quantidade de liga em equilíbrio [3].

Perante o que foi exposto, na busca de reduzir a geração da alumina durante a desoxidação dos aços baixo carbono acalmados ao alumínio, foi elaborada uma metodologia para a realização de corridas experimentais e posteriormente estabelecido um procedimento para garantir a segurança da substituição parcial do alumínio pelo coque nestes aços [4].

\section{MATERIAIS E MÉTODOS}

A prática de desoxidação parcial com coque foi desenvolvida visando os aços com baixo teor de carbono (BC) acalmado ao alumínio produzidos na Aciaria 1 da Usiminas Usina de Ipatinga.

Este desenvolvimento abrangeu as seguintes etapas:

\section{$2.11^{\circ}$ Metodologia}

Nesta fase do trabalho, foi definido o peso máximo de coque a ser adicionado durante o vazamento do aço líquido do convertedor para a panela. Adicionalmente, foram realizadas corridas experimentais com o objetivo de conhecer os efeitos da adição de coque em um aço oxidado (projeções) e o comportamento do carbono do coque adicionado durante o vazamento. Isto se fez necessário, porque em tese, parte do carbono do coque é incorporado ao aço líquido e parte reage com o oxigênio 
dissolvido no aço. Para tanto, foi elaborada uma planilha para efetuar os cálculos do balanço de massa no qual se considerou:

- O teor de carbono de fim de sopro $(A)$;

Incremento de carbono via adição de coque (B);

- Incremento de carbono via adição das ligas (C);

- O teor de carbono final "última amostra do Forno Panela" (D).

$\bar{A}$ equação (3) descreve resumidamente o cálculo do balanço de massa utilizado para prever o teor de carbono final no aço, após as adições de coque e ligas na panela.

$$
(D)=(A)+(B)+(C)
$$

- $(\mathrm{B})=\mathrm{P}_{\text {coque }} \mathrm{X} \% \mathrm{C}$ coque $X \eta_{\mathrm{C} \text { coque. }}$

- $(\mathrm{C})=\mathrm{P}_{\text {liga }} \mathrm{X} \% \mathrm{C}$ liga $X \eta_{\mathrm{C} \text { liga. }}$

$\mathrm{P}_{\text {coque }}=$ peso de coque adicionado;

$\% \mathrm{C}_{\text {coque }}=$ percentual de carbono do coque;

$\eta_{\mathrm{c} \text { coque. }}=$ rendimento do carbono do coque. Indica o percentual do carbono do coque que é incorporado no aço;

$\mathrm{P}_{\text {liga }}=$ peso da liga adicionada;

$\% \mathrm{C}_{\text {liga }}=\quad$ percentual de carbono da liga;

$\eta_{\mathrm{c} \text { liga. }}=\quad$ rendimento do carbono da liga. Indica o percentual do carbono da liga que é incorporado no aço.

\section{$2.22^{\circ}$ Procedimento Operacional}

Após a realização das corridas experimentais, foi definido um padrão de operação, visando à garantia da segurança operacional quando da adição inicial do coque no aço vazado oxidado do convertedor para a panela. Neste procedimento, definiu-se:

_ O momento da adição de coque;

_ O momento da adição de fundentes (cal);

O momento da adição das outras ligas.

Após a definição do padrão operacional, foram produzidas 868 corridas de aços baixo carbono acalmado ao alumínio, desoxidadas parcialmente com coque.

\section{RESULTADOS E DISCUSSÃO}

Desde a implantação do projeto, os aços que foram focados neste trabalho, tiveram a adição de coque em $53 \%$ dos casos. Na tabela 1 é apresentado estratificado por mês o percentual das corridas com a adição de coque como pré-desoxidante.

Tabela 1 - Percentual de corridas que tiveram adição de coque como pré desoxidante mês a mês

\begin{tabular}{cccc}
\hline Mês/Ano & $\begin{array}{c}\mathbf{N}^{\circ} \text { de corridas com } \\
\text { adição de coque }\end{array}$ & $\begin{array}{c}\mathbf{N}^{\circ} \text { de corridas potenciais } \\
\text { que poderiam ter sido } \\
\text { adicionado coque }\end{array}$ & $\begin{array}{c}\text { Percentual de corridas que } \\
\text { tiveram adição de coque }\end{array}$ \\
\hline set/14 & 15 & 160 & $9 \%$ \\
\hline out/14 & 193 & 287 & $67 \%$ \\
\hline nov/14 & 177 & 337 & $53 \%$ \\
\hline dez/14 & 226 & 388 & $58 \%$ \\
\hline jan/15 & 176 & 279 & $63 \%$ \\
\hline fev/15 & 81 & 197 & $41 \%$ \\
\hline Total & 868 & 1648 & $53 \%$ \\
\hline
\end{tabular}


É importante ressaltar que a não adição de coque em alguns aços baixo carbono acalmados ao alumínio, ocorreu com maior frequência quando se obteve teores de carbono de fim de sopro próximos ou maiores que os teores máximos de carbono do limite de especificação para aprovação das corridas.

$\mathrm{Na}$ tabela 2 é apresentada esquematicamente, a quantidade de coque a ser adicionada em função do percentual de carbono de fim de sopro (CFDS), assim como o do \%C máximo da especificação. Os valores de CFDS e dos pesos de coque da tabela 2, são apenas ilustrativos para explicar as ordens de grandeza dos pesos de coque a serem adicionados na corrida.

Tabela 2 - Quantidade de coque a ser adicionada em função do CFDS e do C máximo da sigla

\begin{tabular}{|c|c|c|c|c|c|c|c|c|}
\hline $\begin{array}{c}\text { C MÁXIMO } \\
\text { SIGLA } \\
\text { (\%ppX100) }\end{array}$ & CFDS & $\begin{array}{l}\text { COQUE } \\
\text { "kg" }\end{array}$ & $\begin{array}{l}\text { CFDS } \\
\text { (PPM) }\end{array}$ & $\begin{array}{l}\text { COQUE } \\
\text { "kg" }\end{array}$ & $\begin{array}{l}\text { CFDS } \\
\text { (PPM) }\end{array}$ & $\begin{array}{l}\text { COQUE } \\
\text { "kg" }\end{array}$ & $\begin{array}{l}\text { CFDS } \\
\text { (PPM) }\end{array}$ & $\begin{array}{c}\text { COQUE } \\
\text { "kg" }\end{array}$ \\
\hline 10 & $\leq 100$ & 150 & $100<C \leq 120$ & 100 & $C>120$ & 0 & & \\
\hline 20 & $\leq 100$ & 300 & $100<C \leq 120$ & 200 & $120<\mathrm{C} \leq 140$ & 100 & $C>140$ & 0 \\
\hline
\end{tabular}

Observa-se, que a variável CFDS é quem limita a adição do peso de coque para qualquer faixa de carbono máximo especificado na sigla dos aços baixo carbono acalmados ao alumínio. Ou seja, para um mesmo valor de CFDS, quanto maior for o carbono máximo da especificação, maior será a adição de coque durante o vazamento. Também quanto maior o CFDS, menor ou até mesmo zerada será a adição de coque conforme mostrado na tabela 2.

Para evitar desvios quanto à adição de coque, seja pelo teor de CFDS e/ou pelo carbono máximo da sigla, após a realização das corridas experimentais, foi solicitada à equipe de automação a implantação da tabela 2 no cálculo de adição de liga dos convertedores. Desta forma, as adições ficaram padronizadas no sistema, garantindo assim as adições corretas de coque, eliminando a possibilidade da ocorrência de desvio de corridas, pelo não atendimento do teor de carbono máximo especificado na sigla.

Após a realização das alterações solicitadas no modelo de adições de liga dos convertedores, realizou-se uma reunião com todos os sopradores, líderes de grupo, basculadores e supervisores; visando conscientizar sobre a importância do projeto para a competitividade da Aciaria 1. Após o nivelamento do procedimento com todos os envolvidos no processo e da melhoria realizada no modelo de cálculo de ligas, estabeleceu-se o uso rotineiro do coque como pré desoxidante dos aços baixo carbono acalmados ao alumínio na Aciaria 1, tendo como premissas o cumprimento das adições de coque conforme definidos na tabela 2.

$\mathrm{Na}$ Aciaria 1, os sequenciais médios são da ordem de 90 corridas. Nestas séries, temse uma variação do mix de aços produzidos muito grande, o que dificulta a análise da válvula interna do distribuidor quanto à maior ou menor presença de inclusões não metálicas. Espera-se que, pelo fato de que a desoxidação parcial dos aços baixo carbono acalmados ao alumínio está sendo realizada pelo coque, que a formação da alumina tenha reduzido, melhorando-se assim a limpidez destes aços com consequente melhoria de sua lingotabilidade.

Para verificar a condição da válvula submersa no que diz respeito a níveis de inclusões depositadas, é necessário programar um série de aços baixo carbono acalmados ao alumínio sem a adição de coque e outra com o mesmo tipo de aço realizando a desoxidação parcial com coque. Pode-se afirmar que o fato de reduzir a formação de alumina no aço, quando da adição de coque como pré desoxidante, 
obtém-se uma melhor limpidez no aço, devido à menor formação de inclusões, com consequente melhoria da lingotabilidade.

É importante realizar a contagem de inclusões do aço líquido nas etapas de refino primário e secundário, comparando os resultados com a prática convencional de desoxidação (somente alumínio) com a prática de desoxidação parcial com coque.

Para verificar a eficiência da desoxidação parcial com coque, compararam-se dois meses distintos; sendo, um sem a prática da desoxidação parcial com coque implantada "junho/2014" e outro mês "novembro/2014" com a prática já implantada. Para verificar a similaridade dos teores de carbono de fim de sopro e do alumínio final nos dois períodos analisados, foi feito o teste de comparação das médias e das variâncias para estas duas variáveis. Os resultados são apresentados na tabela 3.

Tabela 3. Média e desvio padrão das variáveis de processo e teste de hipótese para comparação das Médias $(\mu)$ e das variâncias $\left(\sigma^{2}\right)$ (Teores de CFDS e de Alumínio Final)

\begin{tabular}{ccccc}
\hline \multirow{2}{*}{ Variáveis } & \multicolumn{2}{c}{ Junho/2014 (A) } & \multicolumn{2}{c}{ Novembro/2014 (B) } \\
& $\boldsymbol{\mu}$ & $\boldsymbol{\sigma}$ & $\boldsymbol{\mu}$ & $\boldsymbol{\sigma}$ \\
\hline CFDS (ppm) & 393 & 111 & 392 & 109 \\
\hline Alumínio Final (ppm) & 472 & 99 & 460 & 112 \\
\hline
\end{tabular}

Os resultados da tabela 3 , permitem afirmar com $95 \%$ de confiança que as duas variáveis analisadas em períodos distintos, foram estatisticamente iguais. Desta forma, pode-se afirmar que não existe influência dos teores finais de alumínio e do nível de oxidação das corridas, nos resultados médios dos consumos de alumínio e de coque $(\mathrm{kg} / \mathrm{t})$ obtidos nos períodos analisados.

$\mathrm{Na}$ tabela 4 é realizada uma comparação dos consumos de coque e de alumínio nos meses de junho e novembro de 2014.

Tabela 4 - Consumo de coque e de alumínio nos aços baixo carbono acalmado ao alumínio

\begin{tabular}{ccccc}
\hline Mês/Ano & $\begin{array}{c}\text { Média do } \\
\text { CFDS (PPM) }\end{array}$ & $\begin{array}{c}\text { Consumo específico } \\
\text { de Alumínio (Kg/t) }\end{array}$ & $\begin{array}{c}\text { Consumo específico } \\
\text { de coque (Kg/t) }\end{array}$ & $\begin{array}{c}\text { Alumínio médio na } \\
\text { Amostragem final (PPM) }\end{array}$ \\
\hline Jun/14 & 392 & 2,69 & 0,00 & 472 \\
\hline Nov/14 & 393 & 2,43 & 0,22 & 460 \\
\hline
\end{tabular}

Como não foi possível a realização das análises de forma a comparar a presença de inclusões nas válvulas internas, com corridas nas quais se adicionou o coque como pré desoxidante, com corridas nas quais se utilizou somente o alumínio como desoxidante, partiu-se para a análise dos consumos de coque e de alumínio. Pela tabela 4, observa-se que em 11/2014, o consumo específico de alumínio ficou abaixo 0,26 (kg/t) quando comparado com o mês de 06/2014; mês este no qual não foi adicionado o coque como pré desoxidante. Por outro lado, em 11/2014 o consumo específico de coque ficou 0,22 kg/t maior do que o mês de 06/2014. Estes resultados permitem afirmar que nos meses analisados, a substituição do alumínio pelo coque como pré desoxidante é da ordem de 1 para 1; ou seja, para cada quilo de coque adicionado, reduziu-se 1 quilo de alumínio. Considerando que os resultados dos teores médios de carbono "níveis médios de oxidação das corridas" e dos teores finais de alumínio foram considerados iguais, pode-se afirmar que a geração de alumina nas corridas do mês de 11/2014, foi menor quando comparado com o período de 06/2014; período este que a desoxidação foi realizada somente com alumínio. 


\section{CONCLUSÃO}

A prática da desoxidação parcial dos aços acalmados ao alumínio com coque, mostrou-se bastante segura do ponto de vista operacional; dado que em todas as corridas avaliadas, não foi observado nenhum incidente de projeções de aço e/ou escória na panela durante o intervalo que compreende o início e fim de vazamento de aço.

Nas 868 corridas desoxidadas parcialmente com coque, não foram verificados desvios de composição química em relação ao especificado. Assim, entende-se que a prática mostrou-se viável do ponto de vista metalúrgico.

Adicionalmente, a prática desenvolvida propiciou uma redução no consumo específico de alumínio de 0,26 (kg/t), de acordo com os resultados apresentados.

A substituição parcial do alumínio pelo coque, nas condições operacionais da Aciaria 1 é da ordem de 1 para 1; ou seja, em média para cada quilo de coque adicionado, reduziu-se $1 \mathrm{~kg}$ de alumínio.

\section{Agradecimentos}

Os autores agradecem a todos os colaboradores da Aciaria 1, que contribuíram para a concretização deste trabalho.

\section{REFERÊNCIAS}

1 Filho, A.; Souza, C.; Júnior, J.; Freitas, P.; Rocha, S.; Menezes, G.; Souza, H. Carbureto de Cálcio : Uma Alternativa Eficiente ao Uso de Alumínio. ABM, v.10, p. 35-42, 2013.

2 ABAQUS INC. ABACUS Analysis user's manual: version 6-5. Rising Sun Mills, Providence, 2004. V.2.

3 Pennington, T.; Olvey, L. Partial Coke Ladle Desoxidation. Steelmaking Conference Proceedings, 1998. 143-147.

4 Estevão, A.; Araújo, E.; Alves, I. Desoxidação Parcial de Aços Acalmados ao Alumínio com Carbono. Carta Patente $\mathrm{N}^{\circ} \mathrm{PI}$ - 0501625-8. 